\title{
Determinants of malnutrition of under-five children among rural households in the southwest, Nigeria
}

\author{
1,2,3, ${ }^{*}$ Adeyonu, A.G., ${ }^{4}$ Obisesan, A.A. and ${ }^{5}$ Balogun, O.L. \\ ${ }^{1}$ Landmark University SDG 2 (Zero Hunger) \\ ${ }^{2}$ Landmark University SDG 3 (Good Health and Well-being) \\ ${ }^{3}$ Department of Agricultural Economics and Extension, Landmark University, Omu-Aran, Kwara State, \\ Nigeria \\ ${ }^{4}$ Department of Agricultural and Resource Economics, School of Agriculture and Agricultural Technology, \\ The Federal University of Technology P.M.B. 704 Akure Ondo State, Nigeria \\ ${ }^{5}$ Department of Agriculture, School of Science and Technology, Babcock University P.M.B. 4003 Ilishan- \\ Remo Ogun State, Nigeria
}

\author{
Article history: \\ Received: 13 December 2020 \\ Received in revised form: 31 \\ January 2021 \\ Accepted: 29 April 2021 \\ Available Online: 13 \\ February 2022
}

\section{Keywords:}

Malnutrition,

Under-five children,

Rural households,

MUAC tape,

Nigeria

DOI:

https://doi.org/10.26656/fr.2017.6(1).729

\begin{abstract}
Malnutrition has been attributed to many deaths among under-five children in most of the developing countries including Nigeria. Understanding the determinants of malnutrition can provide insights in designing interventions for reducing the high rates of child malnutrition. This study focused on what determines the malnutrition of under-five children among rural households in the southwest, Nigeria. A multistage sampling technique was employed to select 395 households that had 487 under-five children. Data were collected on child's, mother's, household's and community characteristics using a pre-tested structured questionnaire. Information on the child's nutrition status was obtained using Mid Upper Arm Circumference (MUAC) tape. The data were analyzed using descriptive statistics and logit model with STATA 14 statistical package. The results revealed that the average age of under-five children was about 25 months and over $50 \%$ of them are girls with a malnutrition rate of $44.0 \%$. The child's sex, the child's birth interval, cultivated farm size, mother's education, water source, and distance to nearest health center significantly determined the child's malnutrition in rural areas of southwest Nigeria. Given the findings of this research, it is suggested that; mothers should be advised to use contraceptives for child spacing; farmers should be enlightened on the need to implement modern farming practices that lead to optimum yield per land cultivated rather than increasing the size of cultivated farmland; there should be an improvement on women's education as well as a potable water source; and health care facilities close to respondents' residence should be provided.
\end{abstract}

\section{Introduction}

Malnutrition occurs when there is imperfect or bad nutrition. It can be either over or undernutrition. It often starts before the child is giving birth to, and it is directly linked with poverty, low rates of education, and insufficient access to health care facilities (International Food Policy Research Institute, 2014; UNICEF/WHO/ World Bank, 2019). Children become malnourished if they don't have access to adequate nutritious food or if they are infected with diseases that cause undernutrition (WHO, 2006). Many a time, the duo occur together and could be the outcome of many underlying factors such as poor access to food and health care services (WHO,
2010; Akanbiemu, 2014). The nutritional status of any child is an indication of his/her overall health. For children to be well-nourished, they must have access to good nutritious food, be adequately cared for, and not be exposed to repeated illness. With these, they will reach their growth potentials in the long run.

Malnutrition is one of the devastating problems in the world, particularly for the poor and underprivileged. Women of childbearing age and children are highly susceptible to malnutrition as a result of the unfair distribution of food within the household, forbidden diets, transmittable diseases, and lack of adequate care. Child malnutrition is one of the most dreadful challenges 
most poor people in the world are faced with. Globally, acute malnutrition is responsible for over $50 \%$ of mortality in children below the age of five years, implying that annually, about 3.5 million children die of malnutrition. In 2017, about 149 million children (22\%) in the world were stunted (low height-for-age) and about 59 million (40\%) of this were in Africa. In Sub-Saharan Africa, the incidence of child stunting was $34 \%$ and 29.2\% in West Africa Sub-region in 2017 (Food and Agricultural Organization, 2019, UNICEF/WHO/World Bank, 2019). About 20\% of children in developing countries are malnourished (Psaki et al., 2012).

Endemic malnutrition is one of the momentous challenges' children below the age of five years in Nigeria is faced with. Other challenges include high infant mortality rates $(12.5 \%)$, low access to formal education, inadequate access to potable water and sanitation as well as HIV/AIDS (National Population Commission (NPC) and ICF International, 2014). The incidence of stunting is higher in Nigeria than some of her neighbours in the African continent and income peers in other continents (National Bureau of Statistics (NBS), 2015). Global ranking of stunting showed Nigeria to be the $32^{\text {nd }}$ highest out of 136 countries. The report showed that $46 \%$ of under-five children were stunted, $23 \%$ were underweight, while $14 \%$ were wasted (UNICEF/WHO/ World Bank, 2019). Nigeria with a prevalence of $46 \%$ stunted under-five children UNICEF/WHO/World Bank, (2019) is the $12^{\text {th }}$ highest in child malnutrition in the world, ahead of countries like Niger and Rwanda. It is worthy to note that malnutrition rates among under-five children in Nigeria vary significantly across rural-urban areas (Akombi et al., 2019). The outcome of the National Demographic and Health Survey conducted in 2013 showed that the incidence of stunting (acute malnutrition) of under-five children was $37 \%$ and the rate of malnutrition was higher in rural than that of urban communities (NPC, 2014). Also, child malnutrition was said to be more severe among the herders, hired agricultural workers as well as landless smallholder farmers.

In other for the country to achieve the second target of the second and third Sustainable Development Goals (SDGs), concerted effort to reduce under-five malnutrition becomes imperative. The second target of the second SDG is to end all forms of malnutrition by 2030 and achieve the universally approved targets on stunting and wasting in children under five years of age by 2025 . The second target of the third SDG is to end avertible deaths of new-born children and children under the age of five years, with every country aiming to reduce infant mortality to at least as low as $1.2 \%$ live births and under-five mortality to at least as low as $2.5 \%$ live births by 2030. It is important to understand the causes of malnutrition for proper formulation of effective policies that will see to its reduction. Nonetheless, literature is still scanty about what determines the malnutrition of under-five children in rural areas of Nigeria. To the best knowledge of the researchers, only Ijarotimi et al. (2016) and Akombi et al. (2017) have examined factors influencing the malnutrition status of children in Nigeria. This study distinguished itself from previous studies by examining what determined the malnutrition of under-five children among rural households in southwest, Nigeria using MUAC tape to measure child's nutrition status.

\section{Materials and methods}

\subsection{Study area}

This research was conducted in the southwest geopolitical zone of Nigeria. The zone is one of the six geopolitical zones in the country. It is made up of six states which are: Lagos, Oyo, Ogun, Osun, Ondo, and Ekiti. It shares boundaries with Edo and Delta States in the east, Kogi and Kwara States in the North, Atlantic Ocean in the south, and the Republic of Benin in the west. The climate is tropical with a distinct dry season of about five months (November - March) and a wet season of about seven months (April - October). Southwest Nigeria is predominantly agrarian and has about 114,271 land areas (NPC, 2006).

\subsection{Data collection}

The data used for this study were collected through the use of a well-structured pre-tested questionnaire by trained enumerators which include nurses working in rural communities. Information was collected on child's, mother's, households and community-based characteristics. Being the most common tool for measuring child malnutrition status in rural areas, information on the child's malnutrition status was obtained with the use of MUAC tape (Roy, 2000; Khan and Raza, 2014; NBS, 2015). MUAC is a significant measurement tool frequently used for nutrition evaluation among preschool children, and a popular method for measuring a child's anthropometric characteristics in community-based studies (WHO, 1995). MUAC tape is more sensitive and specific than the weight for height procedure, MUAC has a sensitivity and specificity of $24.6 \%$ and $94.8 \%$ respectively (Bobby, 2002). According to Marytt (2006), MUAC appears to be simple, cheap, and acceptable. It seems to be the most popular method in the detection of severe acute malnutrition in children due to its age dependence, sensitivity, specificity, precision, and accuracy.

\subsection{Sampling techniques and sample size}


A representative sample was selected using a multistage sampling technique. At the first stage, two states were randomly selected from the southwest. The stage that followed involved a random selection of one senatorial district from each of these states. At the third stage, two rural Local Government Areas (LGAs) were randomly picked from each of the selected senatorial districts. A list of the villages was obtained from the headquarters of each of the selected LGAs. The fourth stage was the random selection of ten villages from each of the selected LGAs to give a total of 40 villages. The fifth and final stage was the purposive selection of 395 households with at least a child aged 6-59 months using probabilities proportionate to the size of households in each of the selected villages. All the children within the age group in the selected households were included in the study. A total of 487 under-five children were selected for analysis. Data were collected between January and February 2017 which is known as the prehunger season in the zone. The data collected were analysed using STATA 14 statistical package.

The new S0145620 MUAC, Child 11.5 Red/PAC-50 was in order to support execution of the new WHO and UNICEF joint statement on WHO child growth acceptable level and the detection of severe acute malnutrition in children published in May 2009 was employed (NBS, 2015). The tape was designed to identify three distinct categories of a child's nutritional status. The three categories are represented in colour coded Red, Yellow and Green. It is also graduated in millimetres. The standard cut-offs are as presented in Table 1.

Table 1. S0145620 MUAC, Child 11.5 Red/PAC-50 cut off points

\begin{tabular}{lcc}
\hline Colour & Cut-off Point & Nutrition Status \\
\hline Red & $0-11.5 \mathrm{~cm}$ & Malnourished \\
Yellow & $11.5-12.5 \mathrm{~cm}$ & At Risk \\
Green & $12.5-26.5 \mathrm{~cm}$ & Well Nourished \\
\hline
\end{tabular}

\subsection{Analytical techniques}

Logit model was employed to analyse the factors that determined child malnutrition because it is mathematically simple and has asymptotic characteristics which constrained the predicted probabilities to a range of zero to one when compared with Probit. The model is specified as:

logit $P_{i}=\log \left\{\frac{P_{i}}{1-P_{i}}\right\}=\alpha+\beta_{i} X_{i}$

where, $\mathrm{P}$ is the probability of the child nutrition status- 1 if malnourished, 0 otherwise, $\alpha$ is the intercept character, $\beta$ is the vector of slope characters to be estimated, $X$ are the predictor variables (such as child, mother, household and community-based variables) and $i$ indexes individual child aged 6-59 months (children under the age of five years).

The child malnutrition model using the empirical specification above was estimated. The presence of multi -collinearity and heteroscedasticity were checked using appropriate tools before estimating the econometric models. These were done to establish that there was no violation of multiple regression statistical assumptions. The Variance Inflation Factor (VIF) method was employed to detect the presence of multi-collinearity among the explanatory variables. The VIF procedure for each explanatory variable $\left(X_{i}\right)$ was used based on the following formula:

$$
\operatorname{VIF}\left(X_{i}\right)=\left(1-R_{i}^{2}\right)^{-1}
$$

where $R_{i}^{2}$ is the coefficient of determination when $X_{i}$ is regressed on the remaining explanatory variables of the model. A VIF greater than 10 ( $R_{i}^{2}$ exceeds 0.90 ), is used as an indication for the presence of awful multicollinearity (Gujarati, 2006). However, a VIF of 4 was obtained signalling the absence of multi-collinearity among the explanatory variables. In the child malnutrition status regression model, standard errors of the character estimates of the child malnutrition regressions were clustered at the household level to account for interdependence among children observation in the same household. Hence, to correct for unknown forms of the interdependence of observations that may reduce the efficiency of the estimated coefficients, heteroscedasticity consistent standard error (clustered robust estimation) were estimated. Furthermore, since the slope characters obtained from the logit model are not directly interpretable, marginal effects after logit which gave the effects of covariates on the probability of being malnourished were computed and reported (Zewdie and Abebaw, 2013).

\section{Results and discussion}

\subsection{Summary statistics}

Results of summary statistics for some of the independent variables are presented in Table 2. The results showed that the children's mean age stood at 25 months and about $48 \%$ of them were boys. This is in consonance with the findings of (Eshete et al., 2018). A majority of under-five children (89\%) were exclusively breastfed. Furthermore, the results divulged that the mean birth interval was about 29 months and nearly $81 \%$ of the children received all the recommended immunizations. About $91 \%$ of the sample households were headed by males. It is a confirmation of the patriarch nature in Nigeria as it is in most African cultures. This finding agrees with the submission of Kehinde et al. (2021) who submitted that over $90 \%$ of farm households in rural Nigeria are headed by males. 
Table 2. Summary statistics for independent variables

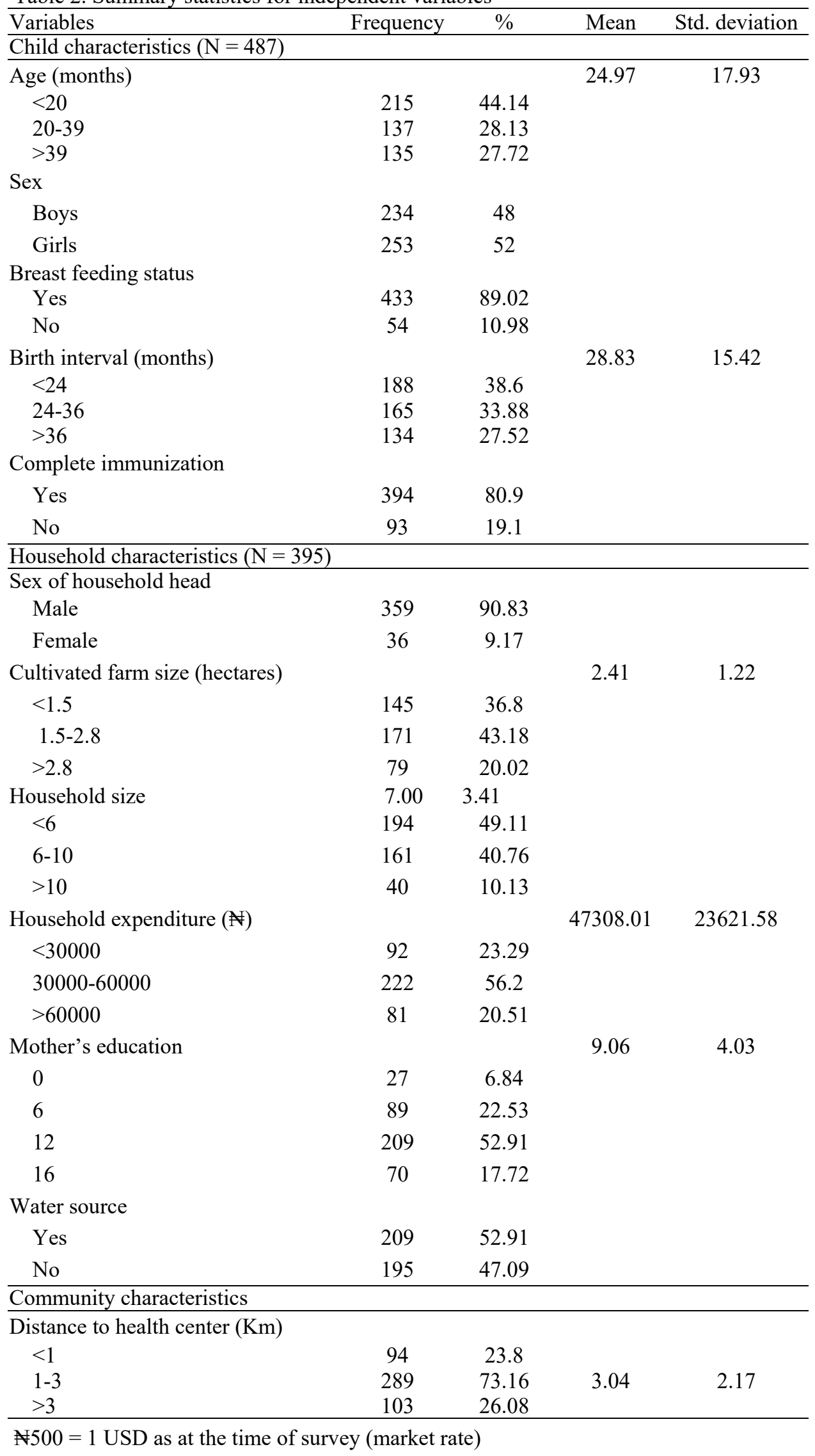

Nearly $85 \%$ of households in Nigeria were headed by a male in 2019 (NBS, 2012; National Population Commission/ICF International, 2014). The results further showed that the average years of schooling of mothers was 9 . With regards to households' monthly expenditure, it ranges from $11900-\$ 9000$ with a mean of \#47308.01.
The mean household size stood at 7 and ranges from 4-28. These are however higher than the 5.4 reported by (NBS, 2020). The mean farm size was 2.4 hectares. This compares well with the national average size of 2.0 hectares. This implies that the farming households are subsistence farmers. This concurs with the findings of NBS (2020) which showed that most of the farmers in 
rural areas of Nigeria are smallholders with less than 10 hectares of farmland. The Source of water has a strong implication on child's malnutrition and morbidity (especially diarrhoea) in many developing countries. The results showed that only $53 \%$ got potable water from a safe source. In rural Nigeria, only $50 \%$ of the households got water from a safe source in 2013 (National Population Commission/ICF International, 2014). The mean distance from the respondents' place of residence to the nearest health centre stood at $3 \mathrm{~km}$ and ranged from $1 \mathrm{~km}-7 \mathrm{~km}$.

\subsection{The incidence of malnutrition}

A healthy and productive generation in the future is only possible with well-nourished children. Pre-school children need adequate nutrition for optimum growth. It is believed that better nutrition and health improve the learning ability of a child. Invariably, it leads to an increase in the strength of the labour force, hence, contributing significantly to economic growth. The results presented in Figure 1 show that about 44\%, 10\%, and $46 \%$ of under-five children respectively were malnourished, at-risk, and well-nourished. About $43 \%$ of under 5 children in rural Nigeria were malnourished in 2013 (National Population Commission/ICF International, 2014). The higher malnutrition rate obtained may not be unconnected with the economic recession experienced in the country in 2016-2017 when this survey was carried out.

Prevalence of malnutrition among under-five children

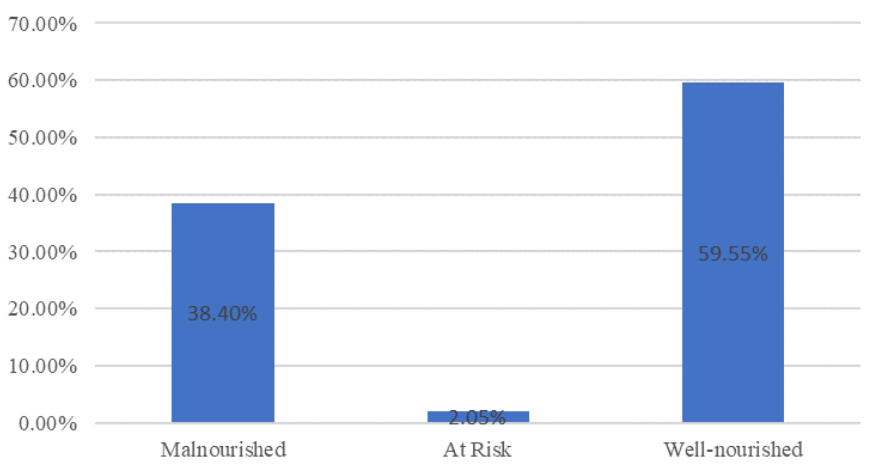

Figure 1. Prevalence of malnutrition among under-five children

\subsection{Determinants of child malnutrition}

In this study, the three categories of under-five children studied were grouped into two to analyse the determinants of child malnutrition. The two categories are malnourished (comprising of malnourished and atrisk) and well-nourished children. This is due to low frequencies in the at-risk children category as opined by (Alom et al., 2009). The results of the logit model are presented in Table 3. As presented in the table, the adjusted $R^{2}$ which indicates the variation in malnutrition explained by the independent variables was $47.2 \%$. Model chi-square was 73.81 and significant at a $1 \%$ level, meaning that all the factors significantly combined to determine the malnutrition status of under-five children in southwest, Nigeria.

A child's sex and child malnutrition status were inversely related, implying that the probability of the boy child being malnourished was lower compared with that of the girl child. The marginal effects indicate that the probability of a boy child being malnourished will be reduced by $0.4 \%$ in the study area. This may not be unconnected with the cultural belief of the importance placed on boy child than girl child in the study area. The findings contradict those of Zewdie and Abebaw (2013), Deshmukh et al. (2013), Asfaw et al. (2015) and Akombi et al. (2019), but in consonance with the submission of Tekile et al. (2019) who reported that male children were more likely to be malnourished in rural areas. A child's birth interval was found to be indirectly associated with malnutrition. The marginal effect implies that ceteris paribus, a unit increase in the birth interval of the child will reduce the likelihood of the child being malnourished by $13.6 \%$. This may be because longer birth-interval between two births permitted for proper use of household resources towards the child, which eventually led to an improvement in the child's nutritional status. The finding is consistent with those of (Roy, 2000; Das et al., 2011; Khan and Raza, 2014). All the researchers opined that a child's birth interval and malnutrition are inversely correlated.

We found an indirect relationship between cultivated farm size and child malnutrition status. This implies that a unit increase in cultivated farm size will result in a decrease in the probability of the child being malnourished by $7.8 \%$ ceteris paribus. This is understandable because produce from cultivated farmland will be consumed by household members and excess can be sold to pay for health expenditures. The finding concurs with that of Zewdie and Abebaw (2013), who reported an indirect relationship between cultivated farm size and child malnutrition.

Mother's level of education is another noteworthy result of this study which was inversely related to child's malnutrition. The results of marginal effects show that all other things being equal, a unit increase in the mother's level of education will decrease the probability of the child being malnourished by $3.1 \%$. This could be due to the beneficial influence of mothers' education on the nutritional status of children which may be through the employment status of mothers. Mother with a high level of education tends to utilize health care facilities better with the high implementation of improved medical 
Table 3. Logit model estimates of child malnutrition in the southwest, Nigeria

\begin{tabular}{lccccc}
\hline Variable & Coefficient & Robust Std. Err. & Marginal effect & Std. Err. & $\mathrm{P}>|\mathrm{z}|$ \\
\hline Child's age & 0.186 & 0.224 & 0.043 & 0.052 & 0.405 \\
Child's sex & -0.019 & 0.006 & $-0.004^{* * *}$ & 0.002 & 0.002 \\
Child's morbidity status & 0.119 & 0.238 & 0.028 & 0.056 & 0.616 \\
Child's birth interval & -0.908 & 0.274 & $-0.136^{* *}$ & 0.058 & 0.026 \\
Immunization & -0.002 & 0.004 & -0.001 & 0.001 & 0.569 \\
Household size & $6.53 \mathrm{E}-06$ & $8.79 \mathrm{E}-06$ & $1.52 \mathrm{E}-06$ & 0.000 & 0.458 \\
Cultivated farm size & -0.334 & 0.089 & $-0.078^{* * *}$ & 0.021 & 0.000 \\
Household expenditure & -0.011 & 0.015 & -0.002 & 0.003 & 0.471 \\
Father's education & -0.035 & 0.034 & -0.008 & 0.007 & 0.299 \\
Mother's education & -0.135 & 0.038 & -0.031 & $0.009^{* * *}$ & 0.000 \\
Water source & -0.828 & 0.264 & -0.197 & $0.062^{* * *}$ & 0.002 \\
Distance to market & 0.033 & 0.050 & 0.008 & 0.012 & 0.501 \\
Distance to health center & 0.461 & 0.100 & 0.107 & $0.023^{* * *}$ & 0.000 \\
Constant & 3.144 & 0.779 & & & 0.000 \\
Adjusted R2 & 0.472 & & & & \\
Model chi square & 73.810 & & & & 0.000 \\
\hline
\end{tabular}

$* *$ and $* * *$ significant at $5 \%$ and $1 \%$ respectively

practices. A high level of education of mothers also guarantees better female independence and in turn affects decisions that border on health, and consequently improvement of child nutritional status (Akombi et al., 2017). This position is consistent with Babatunde et al. (2011), Khan and Raza (2014), Akombi et al. (2019) and Tekile et al. (2019) who posited that child malnutrition and mother's education are indirectly correlated.

Furthermore, water source and child malnutrition were inversely related. The meaning is that children from households that had potable water sources were less likely going to be malnourished compared with their counterparts with unsuitable water sources. From the marginal effect value, the likelihood of the child being malnourished will be reduced by $19.7 \%$ ceteris paribus. This result concurs with that of Zewdie and Abebaw (2013), who reported an inverse relationship between the water source and child malnutrition. Lastly, this study showed a direct association between distance to the health center and child malnutrition status. From the marginal effect value, all other things being equal, a unit increase in distance to the health centre will result in an increase in the probability of the child being malnourished by $10.7 \%$.

\section{Conclusion}

It is obvious from this study that the incidence of under-five children malnutrition was high in southwest, Nigeria. The empirical findings revealed that the determinants of malnutrition are multifaceted and interrelated. They include child's, mother's, household's, and community-based characteristics. The key determinants of malnutrition are a child's sex, child's birth interval, cultivated farm size, mother's education, water source, and distance to the nearest health centre. To reduce the incidence of malnutrition of under-five children in rural areas, this study recommended that: mothers should be advised to use contraceptives for child spacing, farmers should be enlightened on the need to implement modern farming practices that lead to optimum yield per land cultivated rather than increasing the size of cultivated farmland, there should be an improvement in women education and potable water source and health care facilities close to respondents' residents should be provided.

\section{Conflict of interest}

The authors declare no conflict of interest.

\section{Acknowledgements}

The efforts of Mopelola Adesola (graduate student) in collecting part of the data used for this study is appreciated. We also thank the staff nurses in the rural areas who assisted with data collection using MUAC measuring tape.

\section{References}

Akanbiemu, F. (2014). Is household food insecurity a predictor of under-five malnutrition in rural and urban communities of Ondo State, Nigeria? Proceedings of the World Congress of Epidemiology 2014. Anchorage, Alaska USA: International Epidemiological Association.

Akombi, B.J., Agho, K.E., Merom, D., Hall, J.J. and Renzaho A.M. (2017). Multivariate analysis of 
factors associated with wasting and underweight among children under-five years in Nigeria. Nutrients, 44(9), 1-17. https://doi.org/10.3390/ nu9010044

Akombi, B.J., Agho, K.E., Renzaho, A.M., Hall, J.J. and Merom, D.R. (2019). Trends in socioeconomic inequalities in child undernutrition: Evidence from Nigeria Demographic and Health Survey (2003 2013). PLOS ONE, 14(2), e0211883. https:// doi.org/10.1371/journal.pone.0211883

Alom, J., Islam, M.A. and Quddus, A. (2009). Socioeconomic factors influencing nutritional status of under-five children of agrarian families in Bangladesh: A multivariate analysis. Bangladesh Journal of Agricultural Economics, 32(1 and 2), 6374.

Asfaw, M., Wondaferash, M., Taha, M. and Dube, L. (2015). Prevalence of undernutrition and associated factors among children aged between six to fiftynine months in Bule Hora district, South Ethiopia. BMC Public Health, 15, 41. https:// doi.org/10.1186/s12889-015-1370-9

Babatunde, R.O., Olagunju, F.I., Fakayode, S.B. and Sola-Ojo, F.E. (2011). Prevalence and Determinants of Malnutrition among Under-five Children of Farming Households in Kwara State, Nigeria. Journal of Agricultural Science, 3(3), 1-9. https:// doi.org/10.5539/jas.v3n3p173

Bobby, J. (2002). Prevalence of malnutrition in rural Karnataka, South India: a comparison of anthropometric indicators. Journal of Health, Population and Nutrition, 20(3), 239-294.

Das, S. and Rahman, R.M. (2011). Application of ordinal logistic regression analysis in determining risk factors of child malnutrition in Bangladesh. Nutrition Journal, 10(1), 124. https://doi.org/10.1186/14752891-10-124

Deshmukh, P.R., Sinha, N. and Dongre, A.R. (2013). Social determinants of stunting in rural area of Wardha, Central India. Medical Journal Armed Forces India, 69(3), 213-217. https:// doi.org/10.1016/j.mjafi.2012.10.004

Eshete, T., Kumera, G., Bazezew, Y., Mihretie, A. and Marie, T. (2018). Determinants of inadequate minimum dietary diversity among children aged 623 months in Ethiopia: secondary data analysis from Ethiopian Demographic and Health Survey 2016. Agriculture and Food Security, 7, 66. https:// doi.org/10.1186/s40066-018-0219-8

Food and Agricultural Organization. (2019). The State of Food Security and Nutrition in the World. Retrieved on August 20, 2019 from FAO website: http:// www.fao.org/state-of-food-security-nutrition/en/ Gujarati, D.M. (2006). Basic Econometrics. $2^{\text {nd }}$ ed. New Delhi, India: Tata McGraw-Hill Publishing Co. Ltd. Ijarotimi, I.T., Adebiyi, O.A. and Fatiregun, A. (2016). Urban-Rural Disparities and Determinant of Nutritional Status of Under-Five Children: An Example of Akinyele Local Government Area, Ibadan. International Journal of Tropical Disease and Health, 16(1), 1-11. https://doi.org/10.9734/ IJTDH/2016/25292

International Food Policy Research Institute. (2014). Global Nutrition Report 2014: Actions and Accountability to Accelerate the World's Progress on Nutrition. Washington, DC: International Food Policy Research Institute (IFPRI) [In Japanese]. https://doi.org/10.2499/9780896295803

Kehinde, M.O., Shittu, A.M., Adewuyi, S.A., Osunsina, I.O.O. and Adeyonu, A.G. (2021). Land tenure and property rights, and household food security among rice farmers in northern Nigeria. Heliyon, 7, e06110. https://doi.org/10.1016/j.heliyon.2021.e06110

Khan, R.E. and Raza, M.A. (2014). Nutritional Status of Children in Bangladesh: Measuring CIAF and its Determinants. Pakistan Journal of Commerce and Social Sciences, 8(1), 11-23.

Marytt, M. (2006). A review of methods to detect cases of severely malnourished children in the community for their admission into community - best therapeutic care programs. Food and Nutrition Bulletin, 27(3), S7-S23. https:// doi.org/10.1177/15648265060273S302

National Bureau of Statistics (NBS). (2012). Nigeria Social Statistics. Retrieved on June 11, 2017 from NBS website: https://www.nigerianstat.gov.n g/ elibrary

National Bureau of Statistics (NBS). (2015). Report on The Nutrition and Health Situation of Nigeria. Main Report, Abuja. Retrieved on May 27, 2017 from NBS website: https://www.unicef.org/nigeria/ NNHS2015_Final.pdf

National Bureau of Statistics (NBS). (2020). 2019 Poverty and Inequality in Nigeria: Executive Summary. Retrieved on August 03, 2020 from NBS website: https://nigerianstat.gov.ng/elibrary?queries [search] $=$ poverty

National Population Commission (NPC). (2006). National Bureau of Statistics official Gazette. (FGP 71/52007/2 500 (OL.24) Abuja. Retrieved on January 30, 2017 from NPC website: https:// www.nigerianstat.gov.ng

National Population Commission and ICF International. (2014). Nigerian Demographic and Health Survey 
2013, Abuja Nigeria. Maryland, USA: ICF International Rockville.

Psaki, S., Bhutta, Z.A., Ahmed, T., Ahmend, S., Bessong, P., Islam, M., John, S., Kosek, M., Lima, A., Nesamvuni, C., Shrestha, P., Svensen, E., McGarth, M., Richard, S., Seidman, J., Caulfield, L., Miller, M. and Checkley, W. (2012). Household food access and child malnutrition: results from the eight-country MAL-ED study. Population Health Metrics, 10, 24. https://doi.org/10.1186/1478-795410-24

Roy, N. (2000). Use of Mid-upper Arm Circumference for Evaluation of Nutritional Status of Children and for Identification of High-risk Groups for Malnutrition in Rural Bangladesh. Journal of Health, Population and Nutrition, 18(3), 171-180. http://www.jstor.org/ stable/23498874

Tekile, A.K., Woya, A.A. and Basha, G.W. (2019). Prevalence of malnutrition and associated factors among under-five children in Ethiopia: evidence from the 2016 Ethiopia Demographic and Health Survey. BMC Research Notes, 12(1), 391. https:// doi.org/10.1186/s13104-019-4444-4UNICEF/WHO/ World Bank Group (2019). Joint Child Malnutrition Estimates. 2019 edition. Retrieved on May 20, 2020 from UNICEF website: https://www.unicef.org/ media/60626/file/Joint-malnutrition-estimates2019.pdf

World Health Organization (WHO). (1995). Physical Status: the use and interpretation of Anthropometry: Technical Report Series no. 854. Geneva, Switzerland: WHO.

World Health Organization (WHO). (2006). Child growth standards length/height-for-age, weight-forage, weight-for-length, weight-for-height and body mass index-for-age: Methods and development. Geneva: World Health Organization.

World Health Organization (WHO). (2010). World Health Statistics. Retrieved on June 20, 2018 from WHO website: https://www.who.int/gho/ publications/world_health_statistics/

EN_WHS10_Full.pdf

Zewdie, T. and Abebaw, D. (2013). Determinants of Child Malnutrition: Empirical Evidence from Kombolcha District of Eastern Hararghe Zone, Ethiopia. Quarterly Journal of International Agriculture, 52(4), 357-372. DOI: 10.22004/ ag.econ. 173657 